\title{
The impact of employment on quality of life for adults with brain injury
}

\author{
Nicole Ditchman ${ }^{\mathrm{a}, *}$, Julia A. Thomas ${ }^{\mathrm{a}}$, Kristina Johnson ${ }^{\mathrm{b}}$, Christopher Haak ${ }^{\mathrm{c}}$ and Sean Rafajko ${ }^{\mathrm{d}}$ \\ ${ }^{a}$ Department of Psychology, Illinois Institute of Technology, Chicago, IL, USA \\ ${ }^{\mathrm{b}}$ Psychiatry and Behavioral Sciences, Northwestern University Feinberg School of Medicine, Chicago, IL, USA \\ ${ }^{\mathrm{c}}$ Center for Disabilities and Development, University of Iowa, Iowa City, IA, USA \\ ${ }^{\mathrm{d}}$ Gersten Center for Behavioral Health, Chicago, IL, USA
}

Received 6 October 2020

Accepted 24 August 2021

Pre-press 27 November 2021

Published 11 January 2022

\begin{abstract}
.
BACKGROUND: Employment is associated with greater quality of life (QOL) for people with disabilities. Yet, for individuals with traumatic brain injury (TBI), the benefits of work are not often realized given high rates of unemployment.

OBJECTIVE: This study examined the unique impact of psychosocial variables and employment status (working vs. not working) on self-reported QOL among adults with TBI.

METHODS: Participants included 116 adults with TBI between the ages of 18-65, recruited through state brain injury associations in the United States to complete an anonymous online survey. Hierarchical regression analysis was used to examine the incremental impact of psychosocial variables (sense of community, social support, social network, and problemsolving confidence) and employment status on QOL controlling for age and symptom severity.

RESULTS: In the final model, employment status, informal and formal support network ties, problem-solving confidence, sense of community, and emotional support explained 59\% of the variance in QOL, which is considered a large effect size. Employment status uniquely explained 5\% of the variance in QOL.

CONCLUSIONS: Findings support the positive benefits of work for adults with TBI. Rehabilitation services that emphasize vocational considerations and employment supports are needed to impact work status and ultimately QOL for individuals with TBI.
\end{abstract}

Keywords: Brain injury, employment, quality of life, subjective well-being, TBI

\section{Introduction}

Improving quality of life (QOL) and overall well-being is often considered the primary goal of rehabilitation services (Chan et al., 2009; Heinemann \& Mallinson, 2010). Individuals with traumatic brain injury (TBI) exhibit lower QOL on subjective (Brown

\footnotetext{
*Address for correspondence: Nicole Ditchman, PhD, CRC, LCPC, Associate Professor, Department of Psychology, Illinois Institute of Technology, Tech Central, Rm 232, 3424 South State Street, Chicago, IL 60616, USA. Tel.: +1 312567 3511. E-mail: nditchma@iit.edu.
}

\& Vandergoot, 1998; Dijkers, 2004) and objective (Pagulayan et al., 2006) indicators. Thus, efforts to identify and address malleable factors impacting QOL for this population are critical. Employment post-injury is a key element in life satisfaction and QOL (Corrigan et al., 2001; Jacobson et al., 2010; Steadman-Pare et al., 2001; Verdugo et al., 2019), yet most adults with moderate to severe TBI do not return to work (Corrigan et al., 2014; Grauwmeijer et al., 2012; Temkin et al., 2009; van Velzen et al., 2009). In addition to the positive benefits of working, psychosocial variables, such as social support, social 
network, problem solving confidence, and sense of community, appear to be associated with QOL (e.g., Ditchman et al., 2017; Steadman-Pare et al., 2001; Tomberg et al., 2005). However, studies examining correlates and predictors of QOL for people with TBI often fail to examine psychosocial variables in tandem with employment to understand their collective and unique impact on QOL. To address this gap, the purpose of this study was to investigate the incremental influence of a set of psychosocial variables and employment status on perceived QOL in a sample of adults with TBI.

TBI is among the most common type of acquired brain injury and cause of disability in adults (CDC, 2019; Roger et al., 2012). In the United States, there were approximately 2.8 million TBI-related emergency department visits, hospitalizations and deaths in 2013 alone (Taylor et al., 2017). TBI occurs when there is a disruption in the normal function of the brain caused by a bump, blow, or jolt to the head, or by a penetrating head injury (Centers for Disease Control and Prevention [CDC], 2020). The severity of TBI can range from mild to severe, with most TBIs categorized as mild (CDC, 2003). Severity is often determined by criteria including loss of consciousness, duration of post-traumatic amnesia, alterations of consciousness, and/or structural imaging (O'Neil et al., 2013). TBI can lead to impairments in cognitive functioning (e.g., changes in thinking or memory), movement and sensation (e.g., vision or hearing), as well as emotional and personality changes. These changes can affect a person's ability to function in daily life. It is estimated that around 3.2 million people in the United States are living with a TBI-related disability (Zaloshnja et al. 2008). People with moderate to severe TBI are particularly at risk for a variety of long-term health issues that can affect their QOL (Juengst et al., 2015).

QOL is conceptualized in myriad ways and has been measured with a variety of indicators in the existing literature (Dijkers, 2004; Tulsky \& Kisala, 2019). Objective measures, such as socioeconomic and health-related status, provide critical information but often fail to fully capture all contributing factors. An arguably better and increasingly popular approach is to use subjective reports from the individual directly (Michener, 2011). Self-ratings of one's life satisfaction or subjective well-being promote a patient-centered approach by allowing the individual to assess their own QOL. For this reason, subjective evaluations are arguably more valuable than an objective indicator determined by a provider or researcher.
Moreover, self-report of QOL by individuals with disabilities does not align with what might be expected by others (Albrecht \& Devlieger, 1999; Koch, 2000).

Work is an important contributing factor to QOL, and employment has long been associated with psychological health and well-being (Blustein, 2008; Spector, 2005). Work provides material and financial resources necessary for everyday life; however, work is more than just a means towards financial stability. Employment also offers a sense of agency and is central to our lives (Strauser, 2014). Unfortunately, individuals with TBI experience lower rates of employment. In fact, individuals with TBI have a fivefold increased risk of unemployment compared to control groups at one-year post-injury (Doctor et al., 2005). This trend is likely to be further exacerbated with the COVID-19 pandemic, which has disproportionately impacted the employment of people with disabilities (Bureau of Labor Statistics, 2020). Unemployment is a significant threat to self-determination and well-being, and it is well established that individuals with TBI who return to work report higher QOL (Corrigan et al., 2001; Materne et al., 2018). Moreover, individuals with brain injury who never return to work experience significantly greater injury severity and neuropsychological difficulties (Andelic et al., 2012; Fraser et al., 2006), which may have cascading effects on their lives. In a study of prolonged unemployment, Franulic et al. (2004) studied levels of depression and anxiety in persons with brain injury over a ten-year span. Differences in depression and anxiety were not significant at two years post-injury, but unemployed individuals experienced significantly more depression and anxiety at ten years post-injury. Although research suggests employment status is associated with QOL and may buffer against psychological distress (e.g., Verdugo et al., 2019), the strength of the association between employment and subjective QOL, while considering the effect of other salient variables, is not well understood.

There are a number of psychosocial variables correlated with QOL discussed in the literature and relevant in the context of brain injury. Support networks, the systems of relationships that surround an individual, are associated with greater QOL, both in terms of network size (Becker, 1998; Chan \& Lee, 2009; Lim \& Zebrack, 2006) and the quality of social support (Tomberg et al., 2005; Webb et al., 1995). These relationships may be formal (e.g., social workers, physicians, psychologists) or informal (e.g., family and friends; Lim \& Zebrack, 2006). Social support is often derived from these networks. 
Perceived social support refers to the extent to which one feels cared for and supported. Different types of social support exist, including emotional (expressions of empathy, care, and esteem) and instrumental (tangible or informational) support (Cohen \& Wills, 1985; Semmer et al., 2008). Social support is a consistent predictor of QOL for individuals with brain injury (e.g., Ditchman et al., 2017; Seidl et al., 2015; Webb et al., 1995), and individuals with brain injury report less satisfaction with their social support (Tomberg et al., 2005).

Related to social network and supports, the experience of community is also an important factor. Sense of community refers to one's feelings of belonging and influence in a specific community or group (McMillan \& Chavis, 1986). Sense of community and belonging is associated with greater life satisfaction among people with brain injury (Heubner et al., 2003). Moreover, there is evidence that belonging mediates the relationship between brain injury severity and depression outcomes after recovery (Bay et al., 2002). Navigating social and community relationships also involves interpersonal factors, such as problem solving. Problem solving confidence, or self-appraisal of one's problem solving capabilities, constitutes an important consideration for people with TBI who can experience problem solving deficits (Cicerone et al., 2000; Rath et al., 2003). Tsaosides et al. (2009) found that confidence in one's ability to complete daily tasks, make decisions, and handle stress, accounted for $16 \%$ of the variance in QOL among adults with brain injury. Taken together, the impact of employment and these psychosocial variables should be considered when examining QOL in the TBI population.

\subsection{Study purpose}

Employment is often considered an important rehabilitation outcome; however, more research is needed to demonstrate the extent to which employment is associated with greater QOL for people with TBI over and above other psychosocial correlates, such as social networks and support, problem-solving confidence, and sense of community. The purpose of this study was to examine the impact of current employment status (working vs. not working) on the self-reported QOL of adults with TBI, over and above the impact of psychosocial and control variables. We hypothesized that even after controlling for the effects of severity of current symptoms and age, employment status and psychosocial variables related to sense of community, social networks and support, and problem-solving confidence would be uniquely and collectively associated with subjective QOL for working-age adults with TBI.

\section{Method}

\subsection{Participants and procedures}

Participants included 116 adults with self-reported TBI who were recruited through brain injury associations across the U.S. to participate in an anonymous survey study. To be eligible for the study, participants had to be: (a) between the ages of 18 and 65; (b) diagnosed with a brain injury no less than six months previously; and (c) currently residing in the community. The research team reached out to the Brain Injury Association of America (BIAA) as well as individual state brain injury associations and alliances for support in study recruitment. Depending on the state organization preference, the study opportunity was disseminated through emails to membership listservs and/or posted on brain injury organization websites. The online survey was set up through Qualtrics survey software. Institutional Review Board (IRB) approval was obtained prior to the start of the study. Of the 164 questionnaires that were returned by respondents under 65 years old, 27 cases were excluded for not reporting QOL (the dependent variable) and/or work status. Missing values analysis found that data were missing completely at random (Little's MCAR Test: $\left.\chi^{2}(58, N=164)=49.96, p=0.765\right)$. An additional 20 cases were removed for indicating "retired" or "student" to enhance the interpretability of the "work status" variable. Mean substitution was used for continuous psychosocial predictor variables for individuals missing no more than 3 predictor variables ( $n=6$ cases).

Participant characteristics are summarized in Table 1. Participants ranged in age from 21 to 64 years $\operatorname{old}(M=46.5, S D=11.0 ; M d n=46.0)$. More than half of the participants were female $(59.5 \%)$, and the vast majority of the sample described themselves as White $(87.1 \%)$. Nearly all $(95.7 \%)$ of the participants had some post-secondary education, yet most $(62.9 \%)$ of the participants reported being unemployed. Of the 43 participants who were employed, over half $(55.8 \%)$ reported working full-time. The average household income of participants was $\$ 47,717$. When asked about relationship status, just under half of the participants reported having a partner $(43.1 \%)$. The majority 
Table 1

Participant characteristics $(\mathrm{N}=116)$

\begin{tabular}{|c|c|c|c|}
\hline & $N$ & $(\%)$ & $M(S D)$ \\
\hline Age & & & $46.5(11.1)$ \\
\hline \multicolumn{4}{|l|}{ Gender } \\
\hline Male & 44 & $(37.9)$ & \\
\hline Female & 69 & $(59.5)$ & \\
\hline Missing & 3 & $(2.6)$ & \\
\hline \multicolumn{4}{|l|}{ Race $^{\mathrm{a}}$} \\
\hline White & 101 & $(87.1)$ & \\
\hline Hispanic/Latinx & 7 & $(6.0)$ & \\
\hline Native American & 9 & (7.8) & \\
\hline Other & 4 & $(3.4)$ & \\
\hline \multicolumn{4}{|l|}{ Relationship Status } \\
\hline Single & 64 & $(62.0)$ & \\
\hline Partnered or married & 50 & $(43.1)$ & \\
\hline Missing & 2 & $(1.7)$ & \\
\hline \multicolumn{4}{|l|}{ Employment Status } \\
\hline Employed full-time & 24 & $(20.7)$ & \\
\hline Employed part-time & 19 & $(16.4)$ & \\
\hline Not employed & 73 & $(62.9)$ & \\
\hline Annual household income & & & $\begin{array}{c}\$ 47,717 \\
(\$ 43,881)\end{array}$ \\
\hline \multicolumn{4}{|l|}{ Level of Education } \\
\hline Secondary education or less & 5 & $(4.3)$ & \\
\hline Some college education & 33 & $(28.4)$ & \\
\hline College graduate & 44 & $(37.9)$ & \\
\hline Graduate or advanced degree & 34 & $(29.3)$ & \\
\hline \multicolumn{4}{|l|}{ Cause of brain injury ${ }^{\mathrm{a}}$} \\
\hline Motor vehicle accident & 79 & $(68.1)$ & \\
\hline Fall & 24 & (20.7) & \\
\hline Assault & 19 & (16.4) & \\
\hline Other & 35 & $(30.2)$ & \\
\hline \multicolumn{4}{|l|}{ Severity of injury (self-report) } \\
\hline Mild & 15 & $(12.9)$ & \\
\hline Moderate & 47 & $(40.5)$ & \\
\hline Severe & 53 & $(45.7)$ & \\
\hline Missing & 1 & $(0.9)$ & \\
\hline Years since injury & & & $14.2(12.0)$ \\
\hline
\end{tabular}

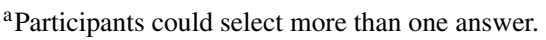

of participants reported a TBI caused by motor vehicle accident $(68.1 \%)$, followed by fall $(20.7 \%)$ and assault (16.4\%). Most participants self-reported their injuries as severe $(45.7 \%)$ or moderate $(40.5 \%)$ and reported an average time since injury of 14.2 years $(M d n=11.2)$. The majority $(82.8 \%)$ reported experiencing post-traumatic amnesia, with 44 (37.9\%) indicating it lasted more than 7 days.

\subsection{Study measures and variables}

\subsubsection{Quality of life (DV)}

The QOL measure was a single-item global QOL question: "How would you rate your overall quality of life?". Participants answered from (1) very poor to (5) very good. Previous research has used this item to capture subjective beliefs of QOL (Das-Gupta \& Turner-Stokes, 2002; Gill \& Feinstein, 1994). In this sample, the mean rating on the QOL scale was 3.36 $(S D=1.02)$.

\subsubsection{Symptom severity}

The short version of the Problem Checklist (PCL; Kayet al., 1995) was used as an indicator of physical and cognitive symptoms related to brain injury. The Physical/Dependency (7 items) and the Cognitive (9 items) subscales were combined for a total symptom severity index. The PCL was adapted from the Head Injury Family Interview and is an inventory of common symptoms following a brain injury. One item from the physical/dependency subscale ("needing supervision") was removed from the scale before data collection began as it did not appear to be a specific symptom. Each item was rated on a 7-point Likert-type scale, ranging from not present (0) to very much (6) to indicate symptom endorsement and the extent to which it was experienced as a problem in the respondent's daily functioning. The PCL has been used with individuals with brain injury previously (Trahan, Pépin, \& Hopps, 2006). It has shown adequate sensitivity in detecting differences between individuals with a brain injury and those without (Paniak et al., 1999). Internal consistency of the composite scale was supported in this study, with Cronbach's alpha of 0.94 .

\subsubsection{Social support}

Perceived social support was measured using the National Institute of Health (NIH) Social Relationship Scales (Cyranowski et al., 2013), specifically the emotional support and instrumental support subscales were used in this study. The 8-item emotional support scale measures perceived availability of emotional support (e.g., "I have someone I trust to talk with about my problems."). The 8-item instrumental support scale measures perceived availability of support for help with daily activities, such as housekeeping, transportation, and errands (e.g., "I have someone to pick up medicine for me if I need it."). Items were rated from never (1) to always (5). Factor analysis has supported the multidimensional nature of the scale (Cyranowski et al., 2013). Internal consistency estimates for the emotional and instrumental scales in this study were 0.97 and 0.96 , respectively.

\subsubsection{Sense of community}

The Sense of Community Index-2 (SCI-2; Chavis et al., 2008), based on McMillan and Chavis' (1986) four-dimensional theory of sense of community, was used to measure sense of community. The SCI- 2 is a 
24-item scale with item ratings ranging from 1 (not at all) to 4 (completely). In this study, participants were asked to reflect on their town. The overall score on the SCI-2 was used as the measure for this study. The SCI- 2 consists of items on four subscales related to feelings of community membership (e.g., "I can trust people in this community"), reinforcement of needs (e.g., "This community has been successful in getting the needs of its members met"), influence (e.g., "This community has good leaders") and shared emotional connection with other community members (e.g., "I am with other community members a lot and enjoy being with them"). The SCI-2 has been widely used, including with individuals with brain injury (Ditchman et al., 2017). In this study, internal consistency was supported with Cronbach's alpha of 0.95 for the total score.

\subsubsection{Problem-solving confidence}

Self-appraised problem-solving abilities were measured using the problem-solving confidence (PSC) subscale from the Problem Solving Inventory (PSI) (Heppner \& Peterson, 1982). This 11-item subscale measures one's confidence in problem-solving skills, such as "When faced with a novel situation, I have confidence that I can handle problems that may arise." Factor loadings for the items on the PSC subscale have ranged from 0.42 to 0.75 (Heppner \& Peterson, 1982) and it has been used with individuals with brain injury (e.g., Batchos et al., 2018). For the present study sample, Cronbach's alpha was 0.92 .

\subsubsection{Social network}

The Social Network Measure (Lim \& Zebrack, 2006; Zebrack \& Chesler, 2000) was used to measure an individual's access to social network roles. This measure has two subscales: informal and formal sources of support. The 7-item informal sources of support subscale measures target relationships including: spouse/partners, friends, parents, children, in-laws, neighbors, and siblings. The 9-item formal sources of support subscale examines relationships such as social workers, employers, co-workers, physicians, other brain injury survivors, religious leaders, nurses, psychologists, and brain injury support groups. Participants responded with "yes" or "no" to indicate if they had that specific source of support currently in their life. All currently present roles were summed to indicate the total number of informal and formal roles present. The Social Network Mea- sure was created specifically for use with individuals with disability (Lim \& Zebrack, 2006; Zebrack, 2000; Zebrack \& Chesler, 2000). This measure has been used previously to demonstrate the association between social network size and QOL variables (Lim $\&$ Zebrack, 2006). In this study, participants identified on average $5.84(S D=2.40)$ out of 0 to 9 possible formal support network roles and $4.98(S D=1.68)$ out of 0 to 7 possible informal support network roles.

\subsection{Data analysis}

Hierarchical linear regression analysis is a form of multiple regression that examines the incremental amount of variance explained by predictor sets entered as separate steps or blocks. This approach is used to statistically control for certain variables to examine if adding variables significantly improves the model's ability to predict the dependent variable. In this study, hierarchical linear regression was used to examine the incremental impact of work status on QOL after controlling for severity of symptoms, age, and psychosocial variables. The change in $R^{2}\left(\Delta R^{2}\right)$ was examined as a measure of each predictor set's contribution. Three blocks were entered to address the research question. In the first block, symptom severity and age were entered as control variables. In the second block, psychosocial variables (sense of community, emotional social support, instrumental social support, informal social network, formal social network, problem solving confidence) were entered. In the final model, work status (employed =1, not employed $=0$ ) was entered. This order of blocks was used to facilitate an understanding of the unique contribution of work status over and above related psychosocial variables on QOL. Significance tests for the regression coefficients for each predictor variable were assessed at each step and at the final model to assess unique relationships to the dependent variable (QOL). A priori power analysis was conducted using $G^{*}$ Power (Faul et al., 2009) and estimated that to achieve a power level of 0.80 with an alpha level of 0.05 , and 9 predictors in multiple regression, the required sample size to detect a medium effect size of $f^{2}=0.15$ was 114 (actual sample size $=116$ ). Prior to the analysis, zero-order correlations were examined for correlations of 0.70 or larger and Variance Inflation Factors (VIF) were examined for scores of 10 or greater (Belsey et al., 1980). VIF scores in this study did not exceed 1.8 suggesting multicollinearity was not a concern. 
Table 2

Study variable correlations, means, and standard deviations $(\mathrm{N}=116)$

\begin{tabular}{|c|c|c|c|c|c|c|c|c|c|c|c|}
\hline Variables & $M(S D)$ & 1 & 2 & 3 & 4 & 5 & 6 & 7 & 8 & 9 & 10 \\
\hline 1. QOL & $3.36(1.01)$ & - & & & & & & & & & \\
\hline 2. Severity & $3.97(1.13)$ & $-0.422^{* * *}$ & - & & & & & & & & \\
\hline 3. Age & $46.50(11.06)$ & $-0.265^{* *}$ & $0.247^{* *}$ & - & & & & & & & \\
\hline 4. PSC & $3.37(0.81)$ & $0.476^{* * *}$ & $-0.590^{* * *}$ & $-0.198^{*}$ & - & & & & & & \\
\hline 5. Informal SN & $4.98(1.68)$ & $0.207^{*}$ & -0.037 & -0.106 & -0.051 & - & & & & & \\
\hline 6. Formal SN & $5.84(2.40)$ & -0.043 & -0.105 & 0.078 & 0.066 & $0.368^{* * *}$ & - & & & & \\
\hline 7. SOC & $1.94(0.60)$ & $0.433^{* * *}$ & $-0.209^{*}$ & -0.085 & $0.273^{* *}$ & 0.093 & 0.176 & - & & & \\
\hline 8. Instrumental SS & $3.31(1.20)$ & $0.352^{* * *}$ & $-0.202^{*}$ & $-0.263^{* *}$ & $0.273^{* *}$ & $0.221^{*}$ & 0.033 & $0.270^{* *}$ & - & & \\
\hline 9. Emotional SS & $3.57(1.11)$ & $0.573^{* * *}$ & $-0.190^{*}$ & $-0.206^{*}$ & $0.324^{* * *}$ & 0.161 & -0.064 & $0.326^{* * *}$ & $0.514^{* * *}$ & - & \\
\hline 10.Work status & $0.37(0.49)$ & $0.360^{* * *}$ & $-0.277^{* *}$ & $-0.343^{* * *}$ & 0.104 & 0.178 & $0.289^{* *}$ & 0.101 & 0.117 & 0.171 & - \\
\hline
\end{tabular}

Note . Severity = symptom severity; $\mathrm{PSC}=$ problem-solving confidence; $\mathrm{SN}=$ social network $\mathrm{SOC}=$ sense of community; $\mathrm{SS}=$ social support; work status = employed (1) vs. not employed $(0) .{ }^{*} p<0.05 ;{ }^{* *} p<0.01 ;{ }^{* * *} p<0.001$.

Table 3

Hierarchical regression model for quality of life $(\mathrm{N}=116)$

\begin{tabular}{|c|c|c|c|c|c|c|c|c|c|}
\hline & \multirow[b]{2}{*}{ Variable } & \multirow[b]{2}{*}{$R^{2}$} & \multirow[b]{2}{*}{$\Delta R^{2}$} & \multicolumn{3}{|c|}{ At entry into model } & \multicolumn{3}{|c|}{ Final model } \\
\hline & & & & $B$ & $S E$ & $\beta$ & $B$ & $S E$ & $\beta$ \\
\hline \multirow[t]{3}{*}{ Step 1} & & $0.21^{* * *}$ & & & & & & & \\
\hline & Symptom severity & & & -0.34 & 0.08 & $-0.38^{* * *}$ & -0.11 & 0.07 & -0.12 \\
\hline & Age & & & -0.02 & 0.01 & $-0.18^{*}$ & 0.00 & 0.01 & 0.02 \\
\hline \multirow[t]{7}{*}{ Step 2} & & $0.53^{* * *}$ & $0.33^{* * *}$ & & & & & & \\
\hline & Sense of community & & & 0.40 & 0.12 & $0.24^{* *}$ & 0.42 & 0.12 & $0.25^{* *}$ \\
\hline & Instrumental social support & & & -0.04 & 0.07 & -0.05 & -0.02 & 0.06 & -0.03 \\
\hline & Emotional social support & & & 0.33 & 0.08 & $0.36^{* * *}$ & 0.29 & 0.07 & $0.32^{* * *}$ \\
\hline & Formal social network & & & -0.07 & 0.03 & $-0.16^{*}$ & -0.10 & 0.03 & $-0.24^{* *}$ \\
\hline & Informal social network & & & 0.12 & 0.05 & $0.19^{*}$ & 0.12 & 0.04 & $0.19^{* *}$ \\
\hline & Problem-solving confidence & & & 0.25 & 0.11 & $0.20^{*}$ & 0.31 & 0.10 & $0.25^{* *}$ \\
\hline \multirow[t]{2}{*}{ Step 3} & & $0.59^{* *}$ & $0.05^{* *}$ & & & & & & \\
\hline & Work status ( 1 = employed $)$ & & & & & & 0.57 & 0.15 & $0.27^{* * *}$ \\
\hline
\end{tabular}

Note. $F(9,106)=16.71, p<0.001$ for the full model; $F(2,113)=14.62, p<0.001$, for Step $1 ; \Delta F(6,107)=12.54, p<0.001$ for Step $2 ; \Delta F$ $(1,106)=13.6, p<0.001$ for Step $3 .{ }^{*} p<0.05 ;{ }^{* *} p<0.01 ;{ }^{* * *} p<0.001$.

\section{Results}

\subsection{Descriptive and correlation analyses}

Means, standard deviations and correlations of the study variables are presented in Table 2 . On average, participants reported moderately positive levels on the 5-point QOL scale $(M=3.36, S D=1.02$, range 1 to 4$)$. QOL was significantly correlated with almost all study variables, with the exception of formal support networks. Moderate to high correlations were found between QOL and symptom severity $(r=-0.42, p<0.001)$, problem solving confidence $(r=0.48, p<0.001)$, sense of community $(r=0.43, p<0.001)$, instrumental social support $(r=0.35, p<0.001)$ and emotional social support $(r=0.57, p<0.001)$. Work status was also significantly correlated with QOL $(r=0.36, p<0.001)$, symptom severity $(r=-0.23, p<0.01)$, age $(r=$ $-0.34, p<0.001)$, and formal support networks $(r=$ $0.29, p<0.01)$.

\subsection{Primary analysis}

To address the research question, a hierarchical regression analysis was used with three sets of predictors included in the regression equation: (a) age and symptom severity; (b) psychosocial variables including sense of community, instrumental social support, emotional social support, formal social networks, informal social networks, and problem-solving confidence; and (c) work status. Results of the analysis are summarized in Table 3 and include unstandardized regression coefficients $(B)$, standard errors $(S E)$, and standardized coefficients $(\beta)$, as well as values of change in $R^{2}\left(\Delta R^{2}\right)$ for the predictor variables at each step and in the final model.

The first step of the regression analysis consisted of age and symptom severity, which accounted for a significant amount of variance in QOL, $R^{2}=0.21, F(2,113)=14.62, p<0.001$. Specifically, symptom severity was negatively associated with QOL such that greater symptom severity was 
associated with poorer reported QOL $(\beta=-0.38$, $t(113)=-4.38, p<0.001)$, as was also the case for younger age $(\beta=-0.17, t(113)=-1.98, p=0.05)$. Psychosocial variables were entered next and accounted for significant variance in QOL as well, $R^{2}=0.53, \Delta R=0.33, F(8,107)=15.30, p<0.001$. Further examination of the standardized partial regression coefficients showed that sense of community $(\beta=0.24, t(107)=3.25, p=0.002)$, emotional social support $(\beta=0.39, t(107)=4.42 p<0.001)$, informal social networks $(\beta=0.19, t(107)=2.56$, $p=0.012)$ and problem solving confidence $(\beta=$ $0.20, t(107)=2.34, p=0.021)$ contributed significantly to the variance in QOL, such that increased presence of these psychosocial variables were associated with greater QOL. Formal social network was inversely associated with QOL at this step $(\beta=-0.16$, $t(107)=-2.11, p=0.037)$. In the final step of the model, work status was entered, which accounted for a significant increase in the variance of QOL explained, $\Delta R^{2}=0.05, F(1,106)=13.60, p<0.001$. Work status contributed significantly to QOL such that employment was associated with greater QOL $(\beta=0.27, t(106)=3.69, p<0.001)$. In the final model, symptom severity $(\beta=-0.12, t(106)=-1.43$, $p=0.138)$ and age $(\beta=0.02, t(106)=0.33, p=0.742)$ were no longer significant predictors.

Overall the full model explained $59 \%$ of the variance of QOL, $R^{2}=0.59, F(9,106)=16.71, p<0.001$. This is considered a large effect size within behavioral science as outlined by Cohen (1988; 1992). After controlling for demographics, severity, and psychosocial variables, work status $(\beta=0.27, p<0.001)$ was the second strongest predictor of QOL after emotional social support $(\beta=0.32, p<0.001)$. These results indicate that participants who are employed reported greater QOL even after controlling for psychosocial correlates.

\section{Discussion}

This study highlights psychosocial factors that are associated with self-reported QOL for adults with TBI and provides support for the unique positive benefits associated with employment. Results revealed 59\% of the variance in self-reported QOL was explained by the variable set. Findings underscore the importance of employment's association with QOL even after controlling for related variables. Employment status significantly contributed to unique variance in QOL, even after demographic, disability, and psychosocial variables were included in the model. Although it accounted for a relatively small $(5 \%)$ portion of the variance, employment status was the second strongest predictor in the model, demonstrating that employment is indeed associated with QOL. This supports findings from previous studies documenting the positive relationship between employment and QOL (Corrigan et al., 2001; Materne et al., 2018; O'Neill et al., 1998; Steadman-Pare et al., 2001). Findings from this study extend this previous work by parsing out employment's unique contribution over and above other considerations such as social support, network, and community. Our findings suggest that employment services and supports may be particularly beneficial for promoting QOL, and the role of vocational rehabilitation providers is essential. Previous research supports that individuals who receive vocational interventions are more likely to return to work following injury than nonintervention groups (Kendall et al., 2006; Trexler \& Parrott, 2016). Additionally, individuals with brain injury who participate in vocational rehabilitation services may have other gains related to employment, such as greater and more sustained daily productivity (Niemeier et al., 2010). Although there is evidence to support the benefits of vocational rehabilitation programs to support return-to-work following TBI (see Tyerman, 2012, for a review), vocational rehabilitation services are not always available to people recovering from TBI, and data on their effectiveness are still quite limited (Saltychev et al., 2013). This is particularly critical for those with more severe TBI, as injury severity has been associated with lower rates of return-to-work (Temkin et al., 2009).

Another notable finding of this study is that symptom severity was no longer a significant predictor of QOL when employment was added to the model. This suggests that severity of cognitive and physical symptoms is not as effective in predicting QOL. The utility of focusing on severity to predict or improve QOL misses the larger picture of rehabilitation for people with TBI. Previous research suggests that injury severity is negatively correlated with employment status, such that individuals with severe symptoms are less likely to be employed (Andelic et al., 2012; Jourdan et al., 2013). The current study's findings build upon this to show that the relationship between employment and symptom severity is more complex. One possible explanation may be that employment mediates the relationship between symptoms and QOL. Employment may also increase QOL such that symptom severity is no longer impacting QOL 
as strongly. Employment, then, is a unique component that may help to reduce symptoms and their impact over time. This finding is also consistent with other research. For instance, a study by Pierce and Hanks (2006) found that social integration and participation were the only variables to uniquely predict life satisfaction scores among adults with TBI, even after including disability variables related to body functions and structures. In line with this, our findings suggest that providers of rehabilitation services may find vocational rehabilitation interventions more effective than strategies relying solely on addressing cognitive and physical symptoms.

Our study findings also highlight important psychosocial variables that contribute to QOL. Specifically, sense of community, emotional support, network ties, and problem-solving confidence were found to be independent predictors in the final model. These findings align with previous research that has demonstrated their association with subjective indicators of QOL (Ditchman et al., 2017; Tsaousides et al., 2009). While the main intent of this study was to examine the unique contribution of work status on QOL, the importance of these psychosocial constructs should not be minimized. Emotional social support was the strongest independent predictor in the model, and the relationship between employment status and emotional social support, particularly as they support QOL, warrants further study. Individuals with brain injury benefit from holistic support to better their QOL. Social relationships, as well as problem-solving confidence and a sense of belonging, ultimately strengthen overall life satisfaction. Moreover, many of these constructs are indeed associated with employment status. Interestingly, formal network ties were inversely associated with QOL in the final model, such that participants with a greater number of formal network ties reported lower QOL when accounting for employment status and the other variables in the model. As formal network ties were characterized by connection to various providers and injury support groups, this may suggest that informal network ties are more critical for greater self-reported QOL. An important consideration in the context of work is the informal support relationships that may exist with co-workers. Relationships with both work peers and supervisors have been shown to contribute to perceived organizational support (Shancock et al., 2012), which may enhance QOL for employees.

Finally, an important consideration when interpreting the study findings is that the majority of the participants were White, female, and with higher education levels than what is typical for the TBI population. The lack of diversity in regard to race/ethnicity is an important limitation, especially given the well-documented health disparities for minority individuals with TBI (Arango-Lisprilla et al., 2010), including greater rates of TBI (Langlois et al., 2006) and worse community integration outcomes after injury (Rosenthal et al., 1996). It is unknown if White individuals are more connected to brain injury associations, which may have resulted in the skewed sample. Although this somewhat homogenous sample limits the generalizability of the results, it also presents an opportunity for reflecting on a few points. First, although the vast majority of the sample reported at least some college education, less than $40 \%$ were working at the time of the study - consistent with rates reported in a systematic review by van Velzen et al. (2009). Although there is some evidence that educational level is predictive of work outcomes (Saltychev et al., 2013), our findings underscore the significant impact of TBI on work status, even for those with higher education. Second, it is important to note that women are historically underrepresented and at times excluded from many TBI-related studies. When women are included, they typically make up only a small proportion of study participants (National Institute of Neurological Disorders and Stroke, 2017). This study is unique in that it includes a majority of women. Finally, the sample also is notable in that the average time since injury was over 14 years. While many TBI studies follow participants immediately after injury or for up to a few years, this study focused on individuals connected to brain injury organizations. These participants are in the community and may no longer be receiving rehabilitation resources that are commonly provided by hospital systems or other rehabilitation and adjustment to disability programs following TBI. The benefits of work and access to vocational rehabilitation services may be particularly important for this group.

\subsection{Implications and practice and research}

The findings from this study indicate that employment, in addition to psychosocial variables, offer a unique contribution to overall QOL in adults with brain injury. This means that effective vocational rehabilitation services are critical to ensuring that persons with brain injury achieve higher QOL. For people with disabilities, including those with brain injury, there are several barriers to employ- 
ment, such as transportation (Rosenbloom, 2007); discrimination in the workplace (Shier et al., 2009); and employer concerns such as cost, legal liability, and lack of knowledge of accommodations (Kaye et al., 2011). Strategies to overcome these barriers have been aimed at the system itself (via legislative work, such as the Americans with Disabilities Act), employers, and/or consumers. Employers may assist individuals with TBI by offering gradual return to work options or workplace modifications (Gourdeau et al., 2018) and by dismantling workplace discrimination that individuals face (Stergiou-Kita et al., 2017).

In the United States, the state-federal vocational rehabilitation system is the oldest and most successful public program for supporting the employment of individuals with disabilities, including those with brain injury (Ditchman et al., 2021). This program serves approximately one million individuals per year and plays a large role in helping people with disabilities reach their employment goals (Martin et al., 2010; U.S. Department of Education, 2018). Services are guided by consumer choice and designed to maximize employability, independence, and community (and workplace) participation of people with disabilities by helping them prepare for, secure, maintain, or regain employment. The employment rates of people with disabilities after receiving these services are found to be around 55\% to 60\% (Dutta et al., 2008; Rosenthal et al., 2006; U.S. Department of Education, 2016). Specific vocational rehabilitation services that have the strongest positive impact on employment outcomes for individuals with brain injury served in this program include on-the-job training, job placement, job search assistance, and onthe-job support (Ahonie et al., 2020; Catalano et al., 2006). However, disparities in outcomes have been observed, and research suggests that while these services are beneficial, individuals with brain injury who are of ethnic/racial minority status and those with work disincentives (e.g., receiving disability benefits) are less likely to obtain employment (e.g..., Cardoso et al., 2007; Catalano et al., 2006). Differences in the effectiveness of these services have also been documented across sex, revealing that women with TBI were less likely to be successfully employed through state vocational rehabilitation services than men despite similar injury and demographic characteristics (Bounds et al., 2003).

There are a number of evidence-based strategies to support employment and return to work for individuals with disabilities, including those with brain injury. For example, motivational interviewing is an empirically supported, client-centered approach that can be effective to promote client motivation, address barriers to change, and improve the therapeutic relationship (Chan et al., 2016; Lundahl et al., 2010). It can be used for addressing motivational issues related to employment (Wagner \& McMahon, 2004), and may be a useful strategy for facilitating acceptance of goals, building the working alliance, and promoting engagement in employment services for individuals with brain injury (Medley \& Powell, 2010). Supported employment, or ongoing support services, such as job coaching, also have a strong research base for promoting employment outcomes of people with disabilities (Campbell et al., 2011), and supported employment can be a cost-effective and beneficial approach for adults with brain injury (Caplan et al., 2015; Targett \& Wehman, 2010; Wehman et al., 2003). For more information on these practices, a training toolkit for vocational rehabilitation service providers on evidence-based practices has been developed by the Rehabilitation Research and Training Center on Evidence-Based Practices in Vocational Rehabilitation (RRTC-EBP-VR, 2016) and is available online. Although there are a number of models for brain injury vocational rehabilitation, there is a paucity of high-quality research to evaluate effectiveness (Tyerman, 2012). Recognizing that service needs likely change over time, more research is needed to understand which vocational services and interventions are most effective, for whom and at what stages post-injury.

Finally, it is important to recognize that problemsolving confidence, social support, sense of community, and network ties may be enhanced by work. In the workplace, problems frequently arise; engaging in work may increase an individual's problem-solving confidence as she or he is required to address workplace concerns. Emotional support may increase in the workplace as co-workers, supervisors, and family members help an individual transition back to work. A sense of community may be restored as individuals become re-integrated into the workplace environment. Informal network ties may also develop with regained employment, as individuals may have financial resources and increased motivation to see friends and family outside the workplace.

\subsection{Limitations and future research}

There are several limitations to consider when reviewing the findings of this study that suggest 
areas for future research. First, the sample size was relatively small considering the prevalence of TBI. Despite the study having adequate power to complete the hierarchical regression analysis, an increased sample size could impact the incremental changes between steps. The sample was also predominantly White, female, and with postsecondary education, which does not fully represent the diverse population of those with TBI. Furthermore, individuals who are connected to brain injury networks may have unique experiences of community that may not exemplify the experience of the larger brain injury population. Future research examining these variables should employ larger, more diverse samples of participants to increase the generalizability of findings. It is also important to note that the majority of the participants described their injury as "moderate" or "severe"; however, this categorization was based on self-report rather than a specific medical definition and poses a limitation in characterizing the sample. Second, the self-report nature of this study may also limit the participant sample, in that those with more severe functional difficulties may have challenges completing the survey or submitting it. At the same time, self-report surveys provide a direct perspective from individuals with brain injury rather than proxy measures. For individuals with brain injury, proxy measures may be incongruent with individual ratings for subjective measures, such as satisfaction with social participation (Dawson et al.; Hart et al., 2010). Measuring subjective QOL most accurately captures the individual's perspective, rather than a caregiver or spouse's point of view. A third limitation is that the dependent variable, QOL, was measured using a single item rather than a scale. A single item measure for subjective QOL may be the best way to capture QOL, as it is a rating of the perceived QOL of an individual (Gill \& Feinstein, 1994). In fact, using lengthy scales and assessments may lack the face validity that a single, global rating may provide (De Boer, et al., 2004). However, there are a number of well-validated measures of QOL available. Many of these can be accessed through the TBI-QOL measurement system that provides access to an item bank and freely available scales (Tulsky \& Kisala, 2019; Tulsky et al., 2016). Finally, an important limitation of this study is that data were captured at a single time point. Given the cross-sectional design of this study, hierarchical regression analysis was the strongest statistical approach to determine predictors of QOL. However, the findings are ultimately correlational and causality cannot be assumed. Using a longitudinal approach would provide additional information about the causality of outcomes.

\section{Conclusion}

This study examined psychosocial and employment variables associated with QOL for adults with TBI. Over half (59\%) of the variance in self-reported QOL was explained by the predictor variables, which is considered a large effect size. Study findings also underscore the unique association between employment and QOL for people with TBI and call attention to the employment disparities they face even decades post-injury. Although psychosocial factors are important considerations in this relationship, work is related to greater QOL above and beyond problem-solving confidence, network ties, and sense of community. Employment was also found to be a more effective predictor of QOL than severity of cognitive and physical symptoms. Rehabilitation services that emphasize vocational considerations and employment supports are essential for impacting work status and ultimately QOL for individuals with TBI.

\section{Acknowledgment}

The authors would like to acknowledge and thank the Brain Injury Association of America and all the state Brain Injury Associations and Brain Injury Alliances who assisted with the dissemination of this study. They would also like to thank all the individuals who took part in this study for their time and participation.

\section{Conflict of interest}

The authors declare that they have no conflict of interest.

\section{Ethical approval}

Ethical approval for this study was obtained from Illinois Institute of Technology's Institutional Review Board (IRB \#2013-125).

\section{Funding}

None to report. 


\section{Informed consent}

All participants were informed of the study purpose, risks and benefits and voluntary nature of the study through an informed consent document that appeared before they could begin the survey. Signed informed consent was waived because the only record linking the participant to the research would be the consent document.

\section{References}

Ahonle, Z. J., Barnes, M., Romero, S., Sorrells, A. M., \& Brooks, G. I. (2020). State-federal vocational rehabilitation in traumatic brain injury: What predictors are associated with employment outcomes? Rehabilitation Counseling Bulletin, 63(3), 143-155. https://doi.org/10.1177\%2F0034355219864684

Albrecht, G. L., \& Devlieger, P. J. (1999). The disability paradox: high quality of life against all odds. Social Science \& Medicine, 48(8), 977-988. https://doi.org/10.1016/S02779536(98)00411-0

Andelic, N., Stevens, L. F., Sigurdardottir, S., Arango-Lasprilla, J. C., \& Roe, C. (2012). Associations between disability and employment 1 year after traumatic brain injury in a working age population. Brain Injury, 26, 261-269. https://doi.org/ 10.3109/02699052.2012.654589

Arango-Lasprilla, J. C., \& Kreutzer, J. S. (2010). Racial and ethnic disparities in functional, psychosocial, and neurobehavioral outcomes after brain injury. The Journal of Head Trauma Rehabilitation, 25(2), 128-136.

Batchos, E., Easton, A., Haak, C., \& Ditchman, N. (2018). Social factors predictive of social integration for adults with brain injury. Disability and Rehabilitation, 40(17), 2062- 2069. https://doi.org/10.1080/09638288.2017.1326175

Bay, E., Hagerty, B. M., Williams, R. A., Kirsch, N., \& Gillespie, B. (2002). Chronic stress, sense of belonging, and depression among survivors of traumatic brain injury. Journal of Nursing Scholarship, 34, 221-226. https://doi.org/10.1111/j.15475069.2002.00221.x

Becker, T., Leese, M., Clarkson, P., Taylor, R. E., Turner, D., Kleckham, J., \& Thornicroft, G. (1998). Links between social networks and quality of life: an epidemiologically representative study of psychotic patients in South London. Social Psychiatry and Psychiatric Epidemiology, 33(7), 299-304. https://doi.org/10.1007/s001270050058

Belsey, D. A., Kuh, E., \& Welsch, R. E. (1980). Regression Diagnostics: Identifying Influential Data and Sources of Collinearity. John Wiley \& Sons, Inc. https://doi.org/10.1002/ 0471725153

Blalock, A. C., McDaniel, J. S., \& Farber, E. W. (2002). Effect of employment on quality of life and psychological functioning in patients with HIV/AIDS. Psychosomatics, 43(5), 400-404. https://doi.org/10.1176/appi.psy.43.5.400

Blustein, D. L. (2008). The role of work in psychological health and well-being: A conceptual, historical, and public policy perspective. American Psychologist, 63(4), 228-240. https://doi.org/ 10.1037/0003-066x.63.4.228

Bounds, T. A., Schopp, L., Johnstone, B., Unger, C., \& Goldman, H. (2003). Gender differences in a sample of vocational rehabilitation clients with TBI. NeuroRehabilitation, 18(3), 189-196

Brain Injury Association of America. (2020). Brain Injury Facts and Statistics. Retrieved from https://www.biausa.org/wpcontent/uploads/CYM-Fact-Sheet-March-2020.pdf

Brown, M., \& Vandergoot, D. (1998). Quality of life for individuals with traumatic brain injury: Comparison with others living in the community. The Journal of Head Trauma Rehabilitation, 13(4), 1-23. https://doi.org/10.1097/00001199-19980800000002

Bureau of Labor Statistics. United States Department of Labor. (2020). Persons with a disability: Labor force characteristics. Retrieved from https://www.bls.gov/news.release/pdf/ disabl.pdf

Campbell, K., Bond, G. R., \& Drake, R. E. (2011). Who benefits from supported employment: A meta-analytic study. Schizophrenia Bulletin, 37(2), 370-380. https://doi.org/10.1093/ schbul/sbp066

Caplan, B., Bogner, J., Brenner, L., Twamley, E. W., Thomas, K. R., Gregory, A. M., Jak, A. J., Bondi, M. W., Delis, D. C., \& Lohr, J. B. (2015). CogSMART compensatory cognitive training for traumatic brain injury: Effects over 1 year. Journal of Head Trauma Rehabilitation, 30(6), 391-401. https://doi.org/ 10.1097/HTR.0000000000000076

Cardoso, E., Romero, M. G., Chan, F., Dutta, A., \& Rahimi, M. (2007). Disparities in vocational rehabilitation services and outcomes for Hispanic clients with traumatic brain injury: Do they exist? The Journal of Head Trauma Rehabilitation, 22(2), 85- 94. https://journals.lww.com/headtraumarehab/pages/ default.aspx

Catalano, D., Pereira, A. P., Wu, M. Y., Ho, H., \& Chan, F. (2006). Service patterns related to successful employment outcomes of persons with traumatic brain injury in vocational rehabilitation. NeuroRehabilitation, 21(4), 279-293. https://doi.org/ 10.3233/NRE-2006-21403

Centers for Disease Control and Prevention (2019). Surveillance Report of Traumatic Brain Injury-related Emergency Department Visits, Hospitalizations, and Deaths-United States, 2014. Centers for Disease Control and Prevention, U.S. Department of Health and Human Services. Retrieved from https://www.cdc.gov/traumaticbraininjury/pdf/TBI-Sur veillance-Report-FINAL_508.pdf?fbclid=IwAR1C8v1 yrFlH3 g0vnV9tIIJSgZyKoyf9-ui36oPN0lkvzSmXdeGpTb9oxf0

Centers for Disease Control and Prevention (2020). TBI: Get the Facts. Retrieved from https://www.cdc.gov/injury/features/ traumatic-brain-injury/index.html

Chan, F., Keegan, J., Muller, V., Kaya, C., Flowers, S., \& Iwanaga, K. (2016). Evidence-based practice and research in rehabilitation counseling. In I. Marini \& M. A. Stebnicki (Eds.), Professional practice of rehabilitation counseling (pp. 391412). Springer.

Chan, Y. K., \& Lee, R. P. (2006). Network size, social support and happiness in later life: A comparative study of Beijing and Hong Kong. Journal of Happiness Studies, 7(1), 87-112. https://doi.org/10.1007/s10902-005-1915-1

Chapin, M. H., \& Holbert, D. (2009). Differences in affect, life satisfaction, and depression between successfully and unsuccessfully rehabilitated persons with spinal cord injuries. Rehabilitation Counseling Bulletin, 53(1), 6-15. https:// doi.org/10.1177\%2F0034355209331403

Chavis, D.M., Lee, K. S., \& Acosta, J. D. (2008). The sense of community (SCI) revised: The reliability and validity of the 
SCI-2. In 2nd international community psychology conference, Lisboa, Portugal.

Cicerone, K. D., Dahlberg, C., Kalmar, K., Langenbahn, D. M., Malec, J. F., Bergquist, T. F.,... \& Morse, P. A. (2000). Evidence-based cognitive rehabilitation: Recommendations for clinical practice. Archives of Physical Medicine and Rehabilitation, 81(12), 1596-1615. https://doi.org/10.1053/ apmr.2000.19240

Cohen, S., \& Wills, T. A. (1985). Stress, social support, and the buffering hypothesis. Psychological Bulletin, 98(2), 310-357. https://psycnet.apa.org/doi/10.1037/0033-2909.98.2.310

Cohen, J. (1988). Statistical Power Analysis for the Behavioral Sciences. Routledge Academic.

Cohen, J. (1992). Statistical Power Analysis. Current directions in psychological science, 1(3), 98-101. https://doi.org/10.1111/ 1467-8721.ep10768783

Corrigan, J. D., Bogner, J. A., Mysiw, W. J., Clinchot, D., \& Fugate, L. (2001). Life satisfaction after traumatic brain injury. The Journal of Head Trauma Rehabilitation, 16(6), 543-555.

Corrigan, J. D., Cuthbert, J. P., Harrison-Felix, C., Whiteneck, G. G., Bell, J. M., Miller, A. C.,... \& Pretz, C. R. (2014). US population estimates of health and social outcomes 5 years after rehabilitation for traumatic brain injury. The Journal of Head Trauma Rehabilitation, 29(6), E1-E9.

Cyranowski, J. M., Zill, N., Bode, R., Butt, Z., Kelly, M. A., Pilkonis, P. A.,... \& Cella, D. (2013). Assessing social support, companionship, and distress: National Institute of Health (NIH) Toolbox Adult Social Relationship Scales. Health Psychology, 32(3), 293-301. https://doi.org/10.1037/a0028586

Das-Gupta, R., \& Turner-Stokes, L. (2002). Traumatic brain injury. Disability and Rehabilitation, 24(13), 654-665. https:// doi.org/10.1080/09638280110109282

Dawson, D. R., Markowitz, M., \& Stuss, D. T. (2005). Community integration status 4 years after traumatic brain injury: Participant-proxy agreement. The Journal of Head Trauma Rehabilitation, 20(5), 426-435. https://doi.org/10.1097/ 00001199-200509000-00004

De Boer, A. G. E. M., Van Lanschot, J. J. B., Stalmeier, P. F. M., Van Sandick, J. W., Hulscher, J. B., De Haes, J. C. J. M., \& Sprangers, M. A. G. (2004). Is a single-item visual analogue scale as valid, reliable and responsive as multi-item scales in measuring quality of life? Quality of Life Research, 13(2), 311320. https://doi.org/10.1023/b:qure.0000018499.64574.1f

Dijkers, M. P. (2003). Individualization in quality of life measurement: instruments and approaches. Archives of Physical Medicine and Rehabilitation, 84, S3-S14. https://doi.org/ 10.1053/apmr.2003.50241

Dijkers, M. P. (2004). Quality of life after traumatic brain injury: a review of research approaches and findings. Archives of Physical Medicine and Rehabilitation, 85, 21-35. https://doi.org/ 10.1016/j.apmr.2003.08.119

Ditchman, N., Chan, F., Haak, C., \& Easton, A. B. (2017). Factors impacting sense of community among adults with brain injury. Rehabilitation Psychology, 62(2), 130- 142. https://doi.org/ 10.1037/rep0000139

Ditchman, N., Keegan, J. P., Batchos, E. J., Haak, C. L., \& Johnson, K. S. (2017). Sense of community and its impact on the life satisfaction of adults with brain injury. Rehabilitation Counseling Bulletin, 60(4), 239-252. https://doi.org/ $10.1177 \% 2$ F0034355216661850

Doctor, J. N., Castro, J., Temkin, N. R., Fraser, R. T., Machamer, J. E., \& Dikmen, S. S. (2005). Workers' risk of unemployment after traumatic brain injury: A normed comparison. Journal of the International Neuropsychological Society, 11, 747-752. https://doi.org/10.1017/s1355617705050836

Dutta, A., Gervey, R., Chan, F., Chou, C. C., \& Ditchman, N. (2008). Vocational rehabilitation services and employment outcomes of people with disabilities: A United States study. Journal of Occupational Rehabilitation, 18, 326-334. https:// doi.org/10.1007/s10926-008-9154-z

Faul, F., Erdfelder, E., Buchner, A., \& Lang, A.-G. (2009). Statistical power analyses using $G^{*}$ Power 3.1: Tests for correlation and regression analyses. Behavior Research Methods, 41, 1149-1160. https://doi.org/10.3758/brm.41.4.1149

Franulic, A., Carbonell, C. G., Pinto, P., \& Sepulveda, I. (2004). Psychosocial adjustment and employment outcome 2, 5 and 10 years after TBI. Brain Injury, 18, 119-129. https://doi.org/ 10.1080/0269905031000149515

Fraser, R., Machamer, J., Temkin, N., Dikmen, S., \& Doctor, J. (2006). Return to work in traumatic brain injury (TBI): A perspective on capacity for job complexity. Journal of Vocational Rehabilitation, 25(3), 141-148. https://content. iospress.com/articles/journal-of-vocational-rehabilitation/jvr 00351

Fryer, D. (1986). Employment deprivation and persona agency during unemployment: A critical discussion of Jahoda's explanation of the psychological effects of unemployment. Social Behaviour, 1, 3-23. https://psycnet.apa.org/record/1989-242 90-001

Gill, T. M., \& Feinstein, A. R. (1994). A critical appraisal of the quality of quality-of-life measurements. Journal of the American Medical Association, 272(8), 619-626. https://doi.org/ 10.1001/jama.1994.03520080061045

Gourdeau, J., Fingold, A., Colantonio, A., Mansfield, E., \& Stergiou-Kita, M. (2018). Workplace accommodations following work-related mild traumatic brain injury: What works? Disability and Rehabilitation, 42(4), 552-561. https://doi.org/ 10.1080/09638288.2018.1503733

Grauwmeijer, E., Heijenbrok-Kal, M. H., Haitsma, I. K., \& Ribbers, G. M. (2012). A prospective study on employment outcome 3 years after moderate to severe traumatic brain injury. Archives of Physical Medicine and Rehabilitation, 93(6), 993-999.

Hart, T., Sherer, M., Temkin, N., Whyte, J., Dikmen, S., Heinemann, A. W., \& Bell, K. (2010). Participant-proxy agreement on objective and subjective aspects of societal participation following traumatic brain injury. The Journal of Head Trauma Rehabilitation, 25(5), 339-348. https://doi.org/10.1097/ htr.0b013e3181c7e60b

Heinemann, A. W., \& Mallinson, T. (2010). Functional status and quality-of-life measures. In R. G. Frank, M. Rosenthal, \& B. Caplan (Eds.), Handbook of Rehabilitation Psychology (pp. 147-164). American Psychological Association.

Heppner, P. P., \& Petersen, C. H. (1982). The development and implications of a personal problem-solving inventory. Journal of Counseling Psychology, 29(1), 66- 75. https://doi.apa.org/ doi/10.1037/0022-0167.29.1.66

Huebner, R. A., Johnson, K., Bennett, C. M., \& Schneck, C. (2003). Community participation and quality of life outcomes after adult traumatic brain injury. American Journal of Occupational Therapy, 57, 177-185. https://doi.org/10.5014/ajot.57.2.177

Ibarra, S., Parrott, D., Waldman, W., Hammond, F. M., DillahuntAspillaga, C., \& Trexler, L. (2020). Provision of resource facilitation services for individuals with acquired brain injury 
across the United States: Results of a 2018 resource facilitator provider survey. Brain Injury, 34(6), 732-740

Jourdan, C., Bosserelle, V., Azerad, S., Ghout, I., Bayen, E., Aegerter, P.,... \& Tazarourte, K. (2013). Predictive factors for 1-year outcome of a cohort of patients with severe traumatic brain injury (TBI): results from the PariS-TBI study. Brain Injury, 27(9), 1000-1007. https://doi.org/10.3109/ 02699052.2013.794971

Juengst, S. B., Adams, L. M., Bogner, J. A., Arenth, P. M., O’NeilPirozzi, T. M., Dreer, L. E., Hart, T., Bergquist, T. F., Bombardier, C. H., Dijkers, M. P., \& Wagner, A. K. (2015). Trajectories of life satisfaction after traumatic brain injury: Influence of life roles, age, cognitive disability, and depressive symptoms. Rehabilitation Psychology, 60(4), 353- 364. https:// doi.org/10.1037/rep0000056

Kay, T., Cavallo, M. M., Ezrachi, O., \& Vavagiakis, P. (1995). The Head Injury Family Interview: A clinical and research tool. The Journal of Head Trauma Rehabilitation, 10, 12-31. https://psycnet.apa.org/doi/10.1097/00001199-19950400000004

Kaye, H. S., Jans, L. H., \& Jones, E. C. (2011). Why don't employers hire and retain workers with disabilities? Journal of Occupational Rehabilitation, 21(4), 526-536. https://doi.org/ 10.1007/s10926-011-9302-8

Kendall, E., Muenchberger, H., \& Gee, T. (2006). Vocational rehabilitation following traumatic brain injury: A quantitative synthesis of outcome studies. Journal of Vocational Rehabilitation, 25(3), 149-160. https://content.iospress.com/articles/ journal-of-vocational-rehabilitation/jvr00352

Koch, T. (2000). The illusion of paradox: commentary on Albrecht, G.L. and Devlieger, P.J. (1998). The disability paradox: high quality of life against all odds. Social Science \& Medicine, 50, 757-759. https://doi.org/10.1016/s0277-9536(99)00385-8

Kreuter, M., Sullivan, M., Dahllöf, A. G., \& Siösteen, A. (1998). Partner relationships, functioning, mood and global quality of life in persons with spinal cord injury and traumatic brain injury. Spinal Cord, 36(4), 252- 261. https://doi.org/10.1038/ sj.sc. 3100592

Langlois, J. A., Rutland-Brown, W., \& Thomas, K. E. (2006). Traumatic brain injury in the United States; emergency department visits, hospitalizations, and deaths. Centers for Disease Control and Prevention, National Center for Injury Prevention and Control.

Lim, J. W., \& Zebrack, B. (2006). Social networks and quality of life for long-term survivors of leukemia and lymphoma. Supportive Care in Cancer, 14(2), 185-192. https://doi.org/ 10.1007/s00520-005-0856-x

Lundahl, B. W., Kunz, C., Brownell, C., Tollefson, D., \& Burke, B. L. (2010). A meta- analysis of motivational interviewing: Twenty-five years of empirical studies. Research on Social Work Practice, 20(2), 137-160. https://doi.org/10.1177\%2F1 049731509347850

Martin, R., West-Evans, K., \& Connelly, J. (2010). Vocational rehabilitation: Celebrating 90 years of careers and independence. American Rehabilitation, 15-18.

Matérne, M., Strandberg, T., \& Lundqvist, L. O. (2018). Change in quality of life in relation to returning to work after acquired brain injury: A population-based register study. Brain Injury, 32(13-14), 1731-1739. https://doi.org/10.1080/02699052. 2018.1517224

McMillan, D. W., \& Chavis, D. M. (1986). Sense of community: A definition and theory. Journal of Community Psychology,
14(1), 6-23. https://doi.org/10.1002/1520-6629(198601)14:1 \%3C6::AID-JCOP2290140103\%3E3.0.CO;2-I

Medley, A. R., \& Powell, T. (2010). Motivational interviewing to promote self-awareness and engagement in rehabilitation following acquired brain injury: A conceptual review. Neuropsychological Rehabilitation, 20(4), 481-508. https:// doi.org/10.1080/09602010903529610

National Institute of Neurological Disorders and Stroke. (2017). Understanding traumatic brain injury in women. Retrieved from https://www.ninds.nih.gov/sites/default/files/tbi_work shop_summary_-_december_18-19_2017_508c_0.pdf

Niemeier, J. P., DeGrace, S. M., Farrar, L. F., Ketchum, J. S., Berman, A. J., \& Young, J. A. (2010). Effectiveness of a comprehensive, manualized intervention for improving productivity and employability following brain injury. Journal of Vocational Rehabilitation, 33(3), 167-179. https://doi.org/ 10.3233/JVR-2010-0525

O’Neil, M. E., Carlson, K., Storzbach, D., Brenner, L., Freeman, M., Quiñones, A.,... \& Kansagara, D. (2014). Complications of mild traumatic brain injury in veterans and military personnel: A systematic review. Department of Veteran Affairs (US). Retrieved from https://www.ncbi.nlm.nih.gov/books/ NBK189784/table/appc.t1/

O’Neill, J., Hibbard, M. R., Brown, M., Jaffe, M., Sliwinski, M., Vandergoot, D., \& Weiss, M. J. (1998). The effect of employment on quality of life and community integration after traumatic brain injury. The Journal of Head Trauma Rehabilitation, 13(4), 68- 79. https://psycnet.apa.org/doi/10.1097/ 00001199-199808000-00007

Pagulayan, K. F., Temkin, N. R., Machamer, J., \& Dikmen, S. S. (2006). A longitudinal study of health-related quality of life after traumatic brain injury. Archives of Physical Medicine and Rehabilitation, 87(5), 611-618. https://doi.org/ 10.1016/j.apmr.2006.01.018

Paniak, C., Phillips, K., Toller-Lobe, G., Durand, A., \& Nagy, J. (1999). Sensitivity of three recent questionnaires to mild traumatic brain injury-Related effects. The Journal of Head Trauma Rehabilitation, 14(3), 211-219. https://doi.org/ 10.1097/00001199-199906000-00002

Pierce, C. A., \& Hanks, R. A. (2006). Life satisfaction after traumatic brain injury and the World Health Organization model of disability. American Journal of Physical Medicine \& Rehabilitation, 85(11), 889-898. https://doi.org/10.1097/ 01.phm.0000242615.43129.ae

Ra, Y. A., \& Kim, W. H. (2016). Impact of employment and age on quality of life of individuals with disabilities: A multilevel analysis. Rehabilitation Counseling Bulletin, 59(2), 112-120. https://doi.org/10.1177\%2F0034355215573538

Rath, J. F., Hennessy, J. J., \& Diller, L. (2003). Social problem solving and community integration in postacute rehabilitation outpatients with traumatic brain injury. Rehabilitation Psychology, 48(3), 137-144. https://doi.org/10.1037/00905550.48.3.137

Rehabilitation Research and Training Center on Evidence-Based Practices in Vocational Rehabilitation (2016). Evidence-Based Practice Counselor Toolkit Vocational Rehabilitation Curriculum for People with Disabilities. RRTC-07-2013. Retrieved from http://research2vrpractice.org/wp-content/uploads/2016/ 12/Toolkit_Evidence-BasedPractice_RRTConEBPforVR_2016.pdf

Roger, V. L., Go, A. S., Lloyd-Jones, D. M., Adams, R. J., \& Berry, J. D. (2012). Heart disease and stroke statistics: 
2012 update-a report from the American Heart Association. Circulation., 125(1), e2-e220. https://doi.org/10.1161/ CIR.0b013e31823ac046

Rosenbloom, S. (2007). Transportation Patterns and Problems of People with Disabilities. In M. J. Field \& A. M. Jette (Eds.), The future of disability in America (pp. 519-560). Washington, D.C.: The National Academies Press.

Rosenthal, D. A., Chan, F., Wong, D. W., Kundu, M., \& Dutta, A. (2006). Predicting employment outcomes based on race, gender, disability, work disincentives, and vocational rehabilitation service patterns. Journal of Rehabilitation Administration, 29, 223-243.

Rosenthal, M., Dljkers, M., Harrison-Felix, C., Nabors, N., Witol, A. D., Young, M. E., \& Englander, J. S. (1996). Impact of minority status on functional outcome and community integration following traumatic brain injury. The Journal of Head Trauma Rehabilitation, 11(5), 40-57.

Saltychev, M., Eskola, M., Tenovuo, O., \& Laimi, K. (2013). Return to work after traumatic brain injury: Systematic review. Brain Injury, 27(13-14), 1516-1527.

Seidl, J. N. T., Pastorek, N. J., Lillie, R., Rosenblatt, A., Troyanskaya, M., Miller, B. I., Romesser, J., Lippa, S., Sim, A. H., \& Linck, J. (2015). Factors related to satisfaction with life in veterans with mild traumatic brain injury. Rehabilitation Psychology, 60(4), 335-343. https://doi.org/10.1037/ rep0000064

Semmer, N. K., Elfering, A., Jacobshagen, N., Perrot, T., Beehr, T. A., \& Boos, N. (2008). The emotional meaning of instrumental social support. International Journal of Stress Management, 15(3), 235. https://doi.org/10.1037/1072-5245.15. 3.235

Shanock, L. R., Roch, S. G., \& Mishra, V. (2012). Why we should care about exchange relationships with coworkers as well as supervisors: Both fellow employees and the organization benefit. TPM-Testing, Psychometrics, Methodology in Applied Psychology, 19(4), 291-310.

Shier, M., Graham, J. R., \& Jones, M. E. (2009). Barriers to employment as experienced by disabled people: a qualitative analysis in Calgary and Regina, Canada. Disability \& Society, 24(1), 63-75. https://doi.org/10.1080/09687590802535485

Spector, P. E. (2005). Industrial and organizational psychology: Research and practice. Hoboken, NJ: Wiley.

Steadman-Pare, D., Colantonio, A., Ratcliff, G., Chase, S., \& Vernich, L. (2001). Factors associated with perceived quality of life many years after traumatic brain injury. The Journal of head trauma rehabilitation, 16(4), 330-342. https://doi.org/ 10.1097/00001199-200108000-00004

Stergiou-Kita, M., Grigorovich, A., Damianakis, T., Le Dorze, G., David, C., Lemsky, C., \& Hebert, D. (2017). The big sell: Managing stigma and workplace discrimination following moderate to severe brain injury. Work: Journal of Prevention, Assessment, and Rehabilitation, 57(2), 245-258. https:// doi.org/10.3233/wor-172556

Strauser, D. R. (2014). Introduction to the centrality of work for individuals with disabilities. In D. R. Strauser (Ed.), Career development, employment, and disability in rehabilitation (pp. 1-10). Springer.

Targett P., Wehman P. (2011) Return to work after traumatic brain injury: A supported employment approach. In: Schultz I., Rogers E. (eds) Work Accommodation and Retention in Mental Health. Springer. https://doi.org/10.1007/978-1-44190428-7_14
Taylor, C. A., Bell, J. M., Breiding, M. J., \& Xu, L. (2017) Traumatic brain injury-related emergency department visits, hospitalizations, and deaths-United States, 2007 and 2013. MMWR Surveillance Summaries, 66(9), 1-16. doi: 10.15585/ mmwr.ss6609a1

Temkin, N. R., Corrigan, J. D., Dikmen, S. S., \& Machamer, J (2009). Social functioning after traumatic brain injury. The Journal of Head Trauma Rehabilitation, 24(6), 460-467.

Tomberg, T., Toomela, A., Pulver, A., \& Tikk, A. (2005). Coping strategies, social support, life orientation and healthrelated quality of life following traumatic brain injury. Brain Injury, 19(14), 1181-1190. https://doi.org/10.1080/02699050 500150153

Trahan, E., Pépin, M., \& Hopps, S. (2006). Impaired awareness of deficits and treatment adherence among people with traumatic brain injury or spinal cord injury. The Journal of Head Trauma Rehabilitation, 21(3), 226-235. https://doi.org/ 10.1097/00001199-200605000-00003

Trexler, L. E., \& Parrott, D. R. (2018). Models of brain injury vocational rehabilitation: The evidence for resource facilitation from efficacy to effectiveness. Journal of Vocational Rehabilitation, 49, 195-203. https://dx.doi.org/10.3233\%2FJ VR-180965

Tsaousides, T., Ashman, T., Seter, C. (2008). The psychological effects of employment after traumatic brain injury: Objective and subjective indicators. Rehabilitation Psychology, 53(4), 456-463. https://doi.org/10.1037/a0012579

Tulsky, D. S., \& Kisala, P. A. (2019). An overview of the traumatic brain injury-quality of life (TBI-QOL) measurement system. The Journal of Head Trauma Rehabilitation, 34(5), 281-288

Tulsky, D. S., Kisala, P. A., Victorson, D., Carlozzi, N., Bushnik, T., Sherer, M.,... \& Cella, D. (2016). TBI-QOL: Development and calibration of item banks to measure patient reported outcomes following traumatic brain injury. The Journal of Head Trauma Rehabilitation, 31(1), 40-51.

Tyerman, A. (2012). Vocational rehabilitation after traumatic brain injury: Models and services. NeuroRehabilitation, 31(1), 51-62.

U. S. Department of Education (2018). Rehabilitation services Fiscal Year 2019 budget request. Retrieved from https:// www2.ed.gov/about/overview/budget/budget19/justifications/irehab.pdf

U.S. Department of Education (2016), Annual report, fiscal year 2013, Report on federal activities under the Rehabilitation Act. Washington, D.C.: Office of Special Education and Rehabilitative Services, Rehabilitation Services Administration. Retrieved from https://www2.ed.gov/about/reports/annual/ rsa/2013/rsa-2013-annual- report.pdf

Van Velzen, J. M., Van Bennekom, C. A. M., Edelaar, M. J. A., Sluiter, J. K., \& Frings-Dresen, M. H. W. (2009). How many people return to work after acquired brain injury?: A systematic review. Brain injury, 23(6), 473-488.

Verdugo, M. A., Fernández, M., Gómez, L. E., Amor, A. M. \& Aza, A. (2019). Predictive factors of quality of life in acquired brain injury. International Journal of Clinical and Health Psychology, 19, 189-197. https://doi.org/10.1016/ j.ijchp.2019.06.004

Wagner, C. C., \& McMahon, B. T. (2004). Motivational interviewing and rehabilitation counseling practice. Rehabilitation Counseling Bulletin, 47(3), 152-161. https://doi.org/ $10.1177 \% 2$ F00343552040470030401 
Wehman, P., Kregel, J., Keyser-Marcus, L., Sherron-Targett, P., Campbell, L., West, M., \& Cifu, D. X. (2003). Supported employment for persons with traumatic brain injury: A preliminary investigation of long-term follow-up costs and program efficiency. Archives of Physical Medicine and Rehabilitation, 84(2), 192-196. https://doi.org/10.1053/apmr.2003.50027

Zaloshnja, E., Miller, T., Langlois, J. A., \& Selassie, A. W. (2008). Prevalence of long-term disability from traumatic brain injury in the civilian population of the United States, 2005. The Journal of Head Trauma Rehabilitation, 23(6), 394-400. doi: 10.1097/01.HTR.0000341435.52004.ac
Zebrack, B. (2000). Quality of life of long-term survivors of leukemia and lymphoma. Journal of Psychosocial Oncology, 18(4), 39-59. https://doi.org/10.1300/J077v18n04_03

Zebrack, B. J., \& Chesler, M. A. (2000). Managed care: The new context for social work in health care-implications for survivors of childhood cancer and their families. Social Work in Health Care, 31(2), 89-103. https://doi.org/10.1300/j010v 31n02_07 